УДК 621.311.26:006.354

\title{
ОБЗОР ФУНКЦИОНАЛЬНЫХ СХЕМ ДЕЦЕНТРАЛИЗОВАННЫХ СИСТЕМ ЭЛЕКТРОСНАБЖЕНИЯ С ВОЗОБНОВЛЯЕМЫМИ ИСТОЧНИКАМИ ЭНЕРГИИ
}

Андрианова Людмила Прокопьевна

д-р техн. наук, профессор Гузаиров Айнур Ильгизович Голубев Дэнис Михайлович Уфимский государственный нефтяной технический университет

Аннотация: В статье приведена краткая характеристика децентрализованных систем электроснабжения с возобновляемыми источниками энергии (ВИЭ) для удаленных объектов. Представлены модификации функциональных схем индивидуальных систем производства электроэнергии с накопителем, без накопителя, совместной работы с дизельгенератором.

Ключевые слова: возобновляемые источники энергии; децентрализованная система электроснабжения; индивидуальная система электроснабжения; тип генератора; структура систем производства электрической энергии.

\section{OVERVIEW OF FUNCTIONAL SCHEMES OF DECENTRALIZED POWER SUPPLY SYSTEMS WITH RENEWABLE ENERGY SOURCES}

\section{Andrianova Lyudmila Prokopyevna Guzairov Ainur Ilgizovich Golubev Denis Mikhailovich}

\footnotetext{
Abstract: The article provides a brief description of decentralized power supply systems with renewable energy sources (RES) for remote facilities. Modifications of the functional schemes of individual power generation systems with a storage device, without a storage device, and working together with a diesel generator are presented.

Key words: renewable energy sources; decentralized power supply system; individual power supply system; generator type; structure of electric power generation systems.
} 
Децентрализованные системы электроснабжения (ДЦЭС) для энергоснабжения удаленных от центральной энергосистемы в соответствии с ГОСТ $[1,2]$ подразделяются на две категории:

- индивидуальные системы электроснабжения (ИСЭ) для единичного потребителя;

- коллективные системы электроснабжения (КСЭ) для широкого числа потребителей.

ИСЭ включает в себя две подсистемы:

- подсистему производства электроэнергии;

- подсистему потребления электроэнергии для использования произведенной электроэнергии.

КСЭ включает в себя три подсистемы:

- подсистему производства электроэнергии (микроэлектростанцию);

- подсистему распределения электроэнергии для передачи этой электроэнергии отдельным потребителям (микросеть);

- подсистему потребления электроэнергии, включая домашнюю проводку и бытовое электронное оборудование отдельных пользователей.

Параметры электроснабжения могут быть следующими:

- передача электроэнергии на постоянном токе;

- передача электроэнергии на переменном токе с инвертором, являющимся частью генерирующей подсистемы;

- передача электроэнергии обоими способами (на постоянном и переменном токе);

- с одним конечным пунктом доставки электроэнергии (с постоянным или переменным током);

- с несколькими конечными пунктами доставки электроэнергии.

В настоящей статье приведен обзор функциональных схем только для индивидуальных децентрализованных систем электроснабжения.

Структура ДЦЭС с возобновляемыми источниками энергии (ВИЭ) для удаленных объектов определяется типами используемых генераторов, т. е. подсистемой производства электроэнергии [3, 4].

Выбор подсистемы производства электроэнергии зависит от категории надежности электроснабжения потребителей электроэнергии $[1,2]$.

Децентрализованные системы электроснабжения с ВИЭ могут быть не управляемые оперативно (рис. 1) и управляемые оперативно (рис. 2). 


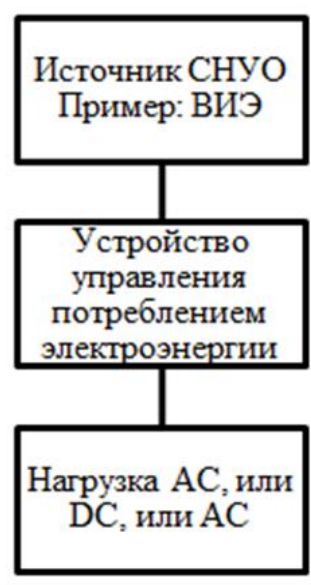

$\boldsymbol{a}$

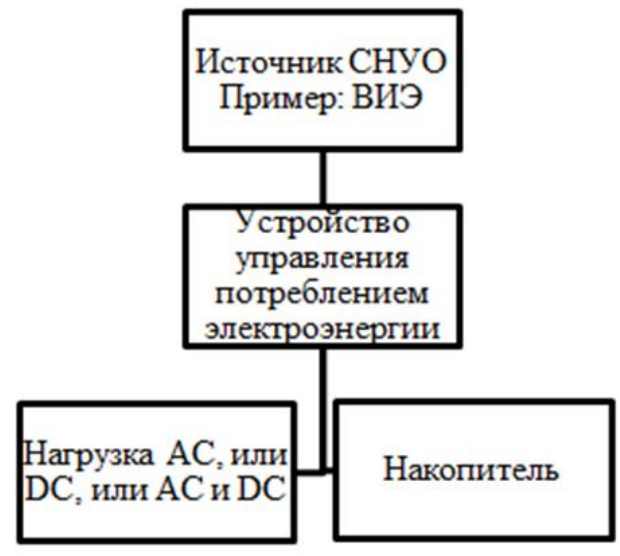

б

\section{Рис. 1. Системы электроснабжения с ВИЭ, не управляемые}

оперативно: $a$ - система без накопителя; $\sigma$ - система с накопителем; СНУО - система не управляемая оперативно;

$\mathrm{AC}$ - нагрузка на переменном токе; DC - нагрузка на постоянном токе [2]

Источник, генератор, система являются не управляемыми оперативно (СНУО), если они зависят от наличия ресурсов, и энергия может быть недоступна в требуемый момент времени.

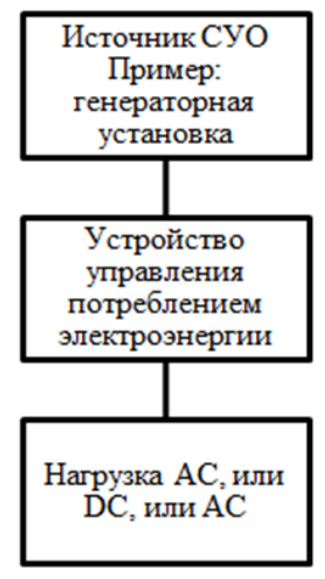

$a$

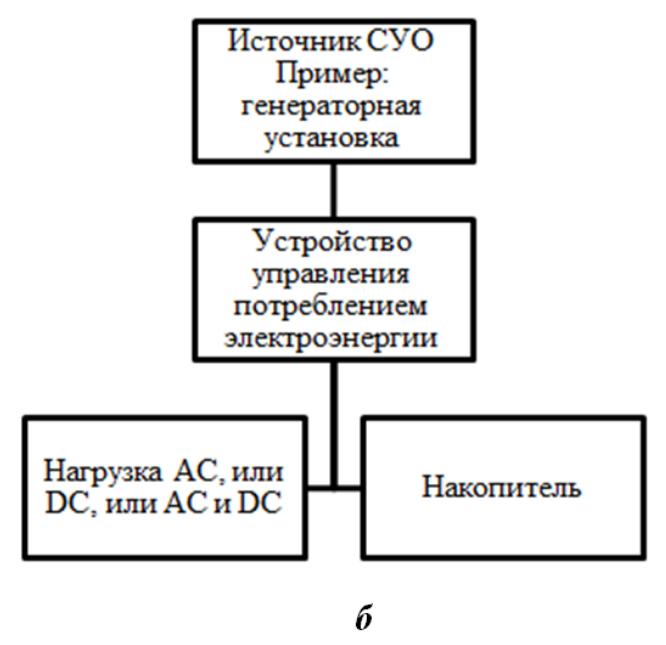

б

Рис. 2. Системы ДЦЭС управляемые оперативно:

$a$ - система без накопителя; $\sigma$ - система с накопителем;

СУО - система управляемая оперативно;

$\mathrm{AC}$ - нагрузка на переменном токе; DC - нагрузка на постоянном токе [2] 


\section{ДОЛГОСРОЧНОЕ РАЗВИТИЕ И ОБЕСПЕЧЕНИЕ КОНКУРЕНТОСПОСОБНОСТИ ОБЩЕСТВА И ГОСУДАРСТВА}

Источник, генератор, система являются управляемыми оперативно (СУО), если энергия, необходимая для поставки, имеется в наличии в любой требуемый момент времени [3, 4].

В качестве примера на рис. 3 показаны структуры комбинированных ДЦЭС, когда в них имеется источник СНУО с ВИЭ, а также СУО с генераторной установкой.

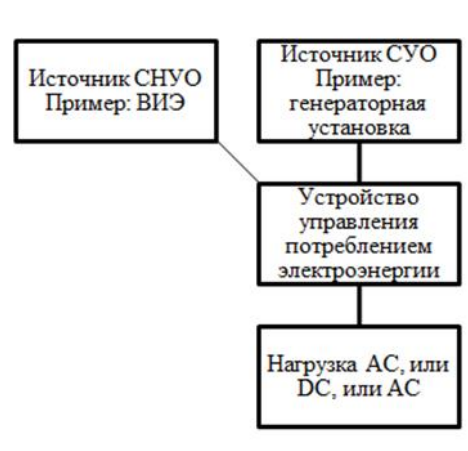

$a$

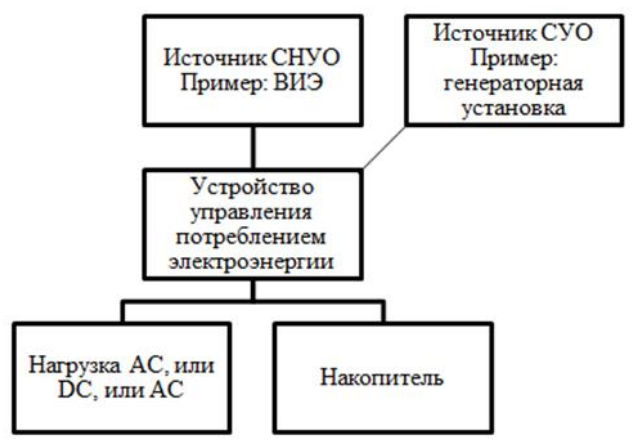

6

Рис. 3. Комбинированные ДЦЭС: СНУО - ВИЭ и СУО - генератор: $a$ - система без накопителя; $\sigma$ - система с накопителем;

СНУО - система не управляемая оперативно;

СУО - система управляемая оперативно; $\mathrm{AC}$ - нагрузка на переменном токе; DC - нагрузка на постоянном токе [2]

Классификация индивидуальных ДЦЭС приведена в таблице 1.

Таблица 1

Классификация ДЦЭС в зависимости от типа генератора [2]

\begin{tabular}{|l|c|}
\hline \multicolumn{1}{|c|}{ Тип генератора } & Обозначение ИСЭ \\
\hline $\begin{array}{l}\text { Только на основе ВИЭ, гибридная или нет, } \\
\text { без накопителя электроэнергии }\end{array}$ & $\mathbf{T}_{\mathbf{1}} \mathrm{I}$ \\
\hline $\begin{array}{l}\text { Только на основе ВИЭ, гибридная или нет, } \\
\text { с накопителем электроэнергии }\end{array}$ & $\mathbf{T}_{\mathbf{2}} \mathbf{I}$ \\
\hline $\begin{array}{l}\text { На основе ВИЭ, гибридная или нет + дизель-генератор, } \\
\text { без накопителя электроэнергии }\end{array}$ & $\mathbf{T}_{\mathbf{3}} \mathbf{I}$ \\
\hline $\begin{array}{l}\text { На основе ВИЭ, гибридная или нет + дизель-генератор, с } \\
\text { накопителем электроэнергии }\end{array}$ & $\mathbf{T}_{\mathbf{4}} \mathrm{I}$ \\
\hline Только дизель-генератор без накопителя ЭЭ & $\mathbf{T}_{\mathbf{5}} \mathbf{I}$ \\
\hline Только дизель-генератор с накопителем ЭЭ & $\mathbf{T}_{\mathbf{6}} \mathrm{I}$ \\
\hline
\end{tabular}




\section{ДОЛГОСРОЧНОЕ РАЗВИТИЕ И ОБЕСПЕЧЕНИЕ КОНКУРЕНТОСПОСОБНОСТИ ОБЩЕСТВА И ГОСУДАРСТВА}

\section{Система типа $\mathrm{T}_{1} \mathrm{I}$ - Производство электроэнергии с помощью ВИЭ -}

это системы без накопителя, работающие в синхронном режиме с ВИЭ, использующими солнечную энергию, энергию ветра или волн.

В зависимости от типа источника электроэнергии (фотоэлектрический генератор или ветродвигатель) и от рода тока (постоянного или переменного) напряжения на выходе системы могут быть предусмотрены модификации системы данного типа, приведенные на рис. 4 (таблица 2).

Таблица 2

\section{Модификации системы типа T1 1}

\begin{tabular}{|c|c|c|}
\hline Тип системы & Источник электроэнергии & $\begin{array}{c}\text { Род тока напряжения на } \\
\text { выходе системы }\end{array}$ \\
\hline $\begin{array}{c}\mathrm{T}_{1} \mathrm{I}-\mathrm{a} \\
\text { (рис. } 4, \mathbf{a})\end{array}$ & $\begin{array}{l}\text { Постоянный ток: фотоэлектрический модуль } \\
\text { (PV-модуль) }\end{array}$ & Постоянный ток \\
\hline $\begin{array}{c}\mathrm{T}_{1} \mathrm{I}-\mathrm{b} \\
\text { (рис. 4, б) }\end{array}$ & Переменный ток: ветродвигатель & Переменный ток \\
\hline $\begin{array}{c}\mathrm{T}_{1} \mathrm{I}-\mathrm{c} \\
\text { (рис. 4, в) }\end{array}$ & $\begin{array}{l}\text { Постоянный ток: фотоэлектрический модуль } \\
\text { (PV-модуль) }\end{array}$ & $\begin{array}{l}\text { Переменный ток } \\
\text { (преобразование) }\end{array}$ \\
\hline $\begin{array}{c}\mathrm{T}_{1 \mathrm{I}^{1-\mathrm{d}}} \\
\text { (рис. 4, г) }\end{array}$ & Переменный ток: ветродвигатель & $\begin{array}{l}\text { Постоянный ток } \\
\text { (преобразование) }\end{array}$ \\
\hline
\end{tabular}

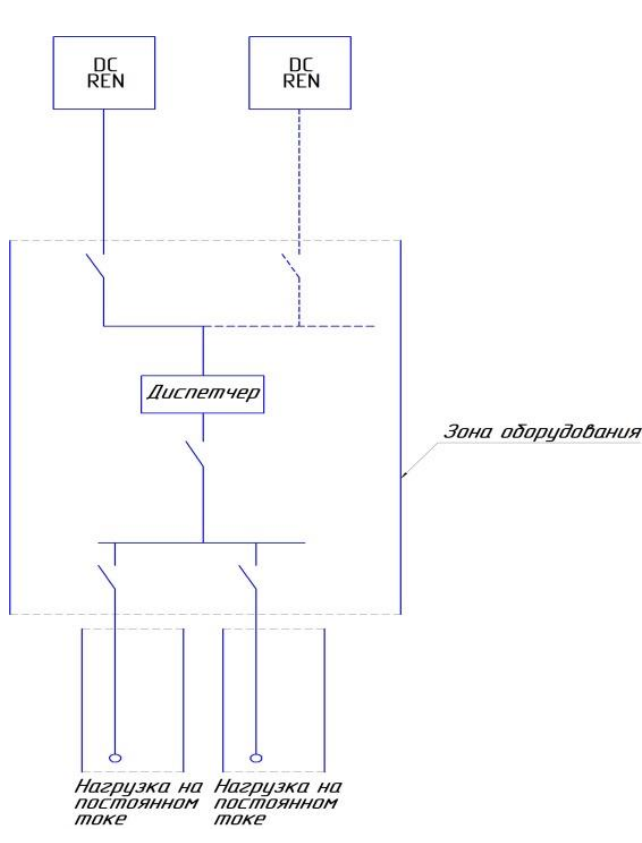

$\boldsymbol{a}$

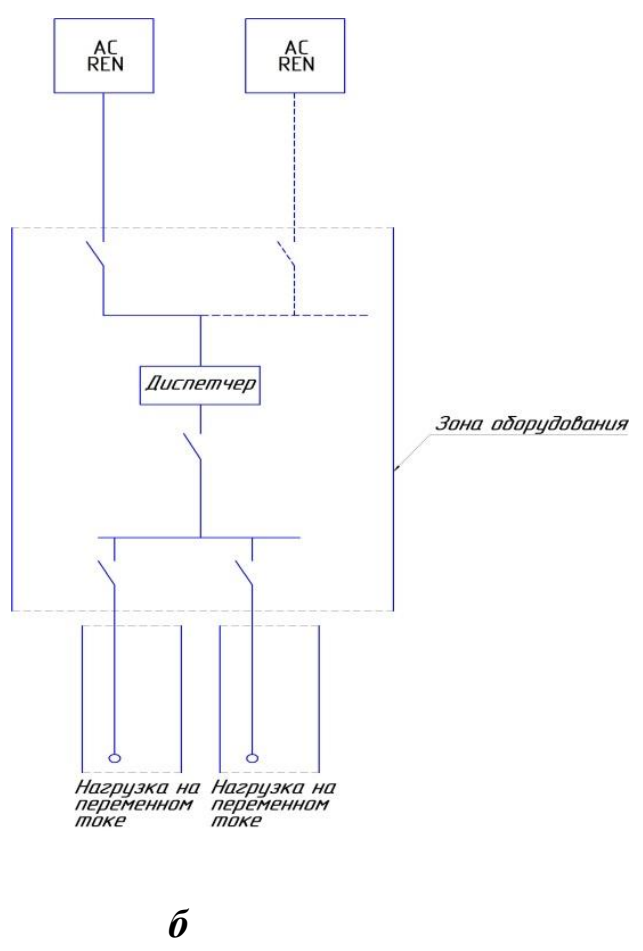



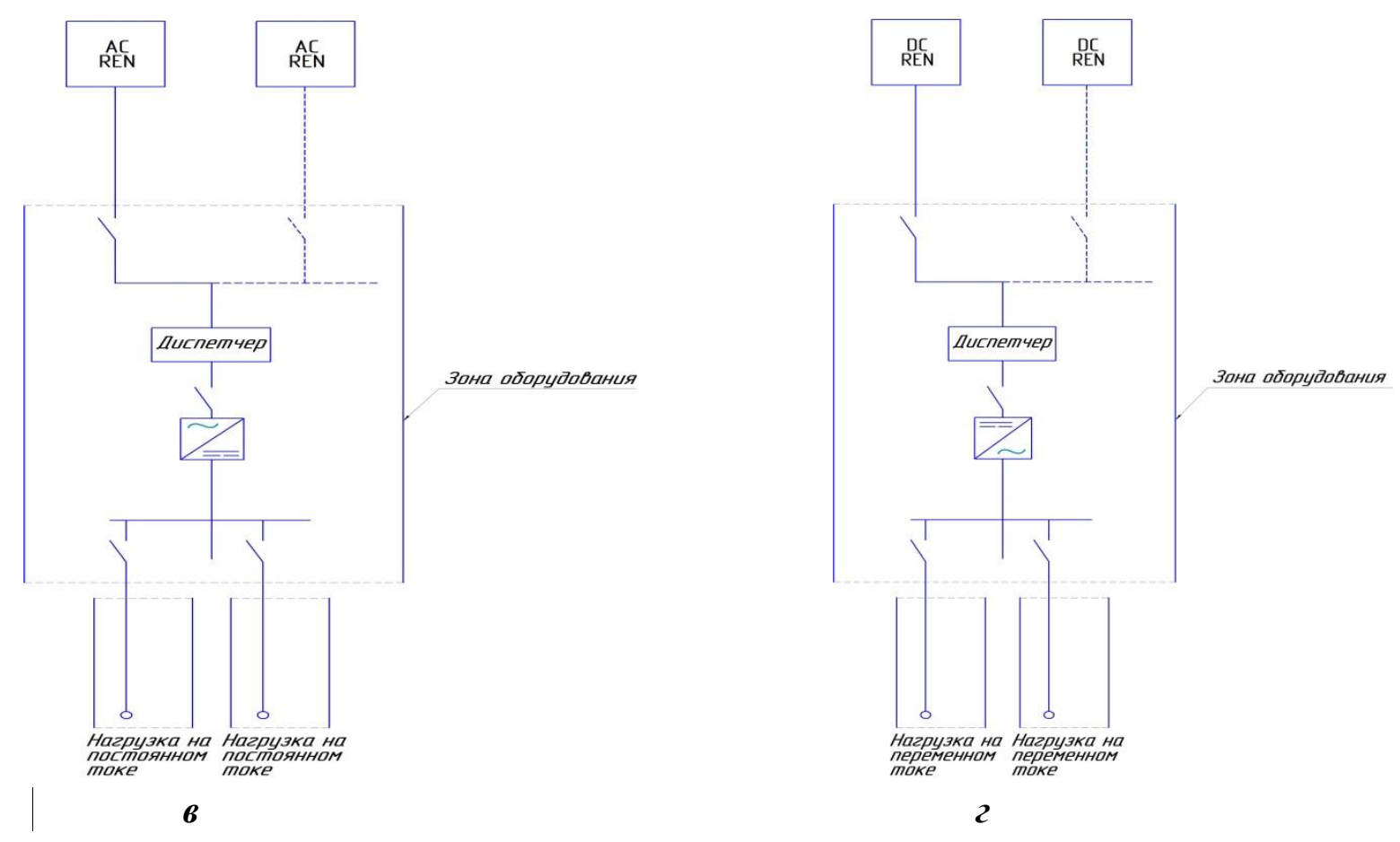

Рис. 4. Системы типа T1 - Производство электроэнергии с помощью ВИЭ без накопителя: $a$ - T11-a; $\sigma$ - T11-b; $\boldsymbol{\theta}$ - T11-c; 2 - T1l-d

Тип $\mathbf{T}_{\mathbf{1}} \mathbf{l}$ системы главным образом предназначен для электропитания оборудования при различного рода процессах в случае, когда нежелательно или невозможно накопление электроэнергии, например, при перекачивании воды, вентиляции помещений и т. д.

Система типа $\mathbf{T}_{2}$ I: Производство с помощью источников на основе ВИЭ при наличии накопителя электроэнергии.

Система типа $\mathbf{T}_{\mathbf{2}} \mathbf{l}$ (рис. 5) предназначена в первую очередь для пользователей, которые хотят получать электроэнергию в облачную или безветренную погоду. Данная система должна иметь способность запасать электроэнергию. Так как требования по резерву не установлены, то потребитель должен осознавать, что ограниченная емкость накопителя периодически будет приводить к перебоям в энергоснабжении [2]. 


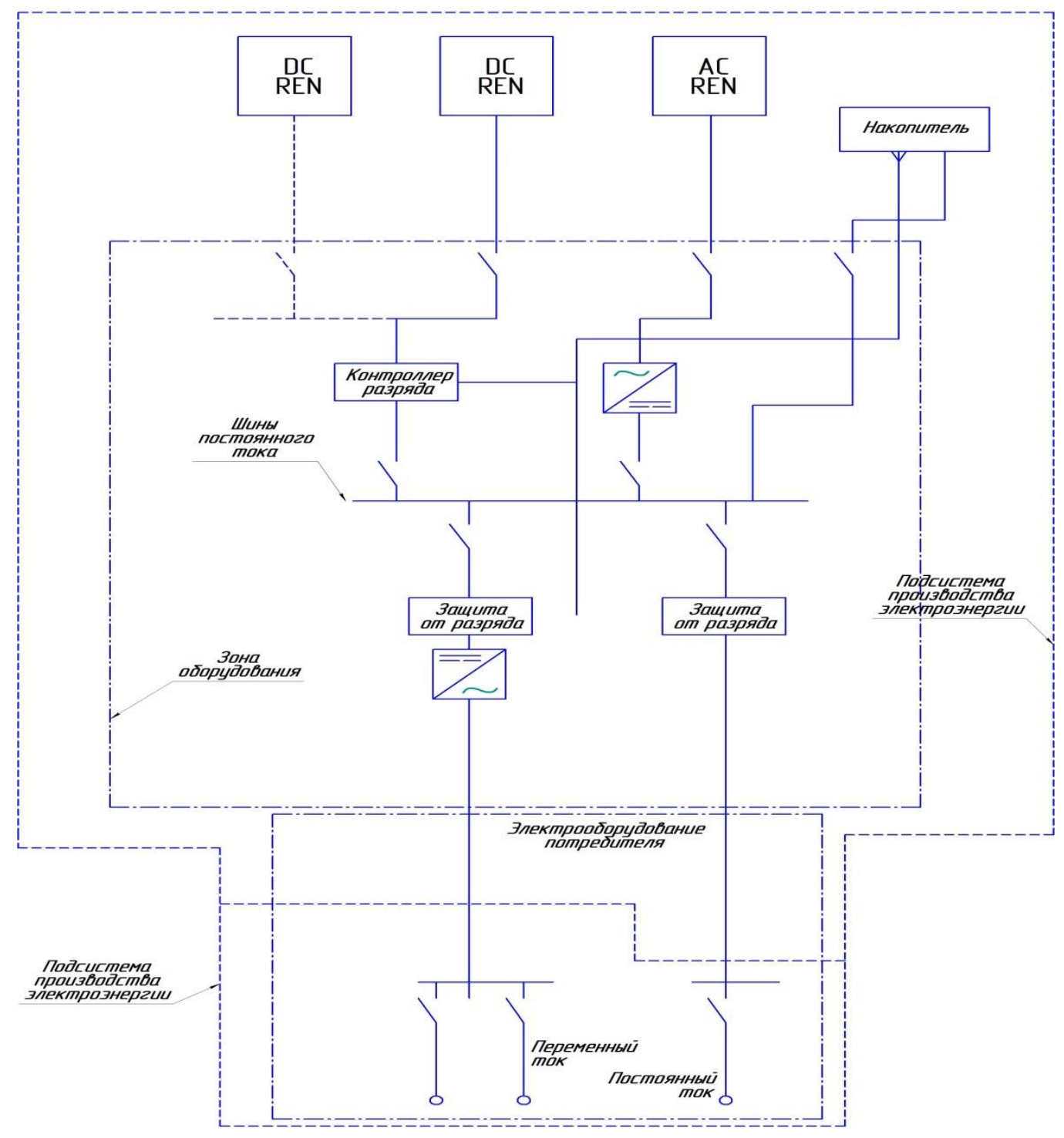

\section{Рис. 5. Система типа T2l - Производство с помощью источников на основе ВИЭ при наличии накопителя электроэнергии}

Электрооборудование потребителя должно быть приведено к номинальному напряжению (например, на напряжение 24 В постоянного тока или 230 В переменного тока). Там, где это необходимо, система должна принимать во внимание ограничения по постоянному току: разъемы питания кабелей, заземления, устройства релейной защиты и т.д.

Электрооборудование потребителя системы типа $\mathbf{T} \mathbf{2} \mathbf{l}$ может работать: только на постоянном токе или только на переменном токе; на постоянном и переменном токе. 
Система типа T, T: $_{3}$ Производство с помощью источников на основе ВИЭ совместно с дизель-генератором без накопителя электроэнергии, представленная на рис. 6.

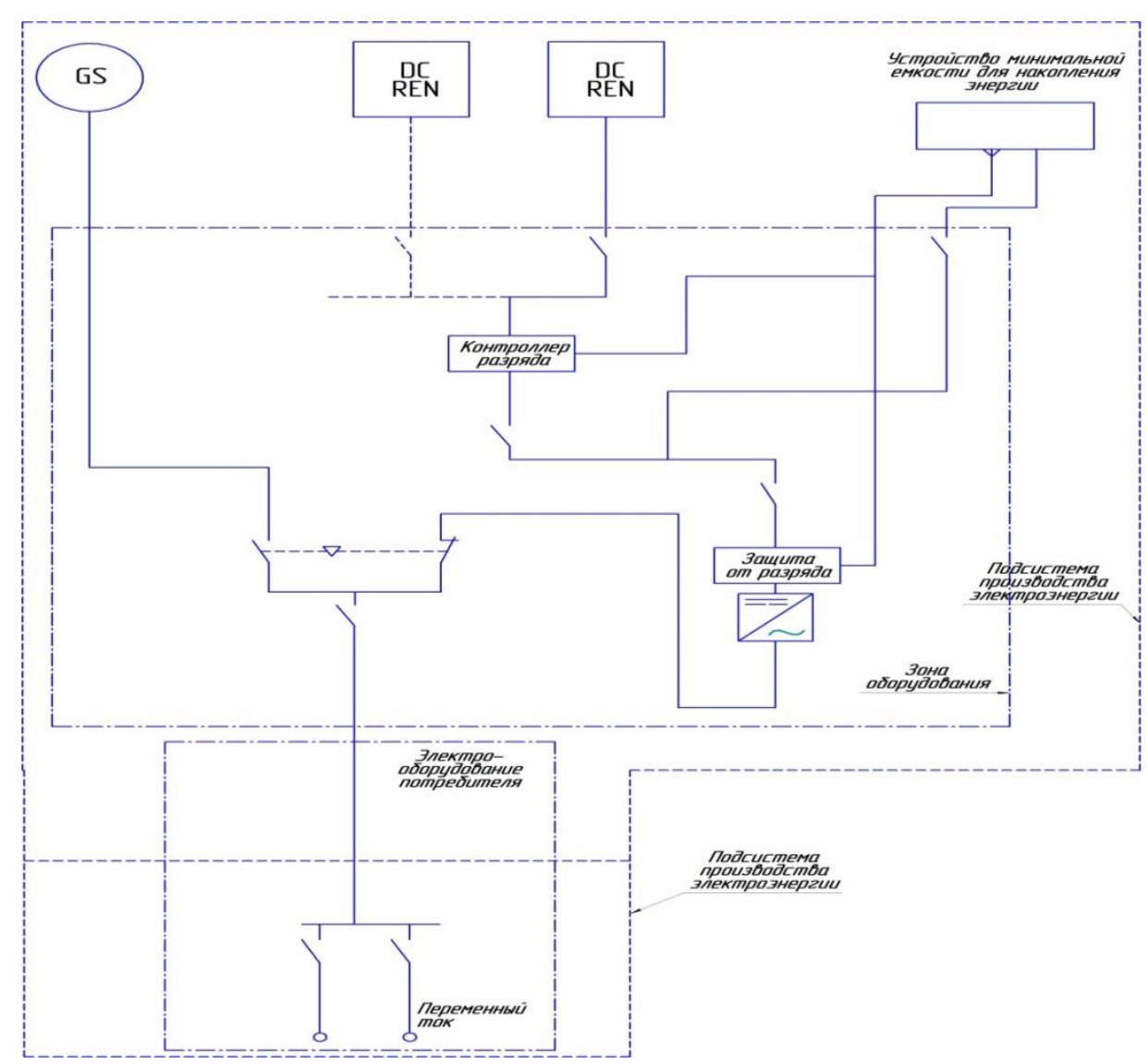

Рис. 6. Система типа $T_{3}$ I -a - Производство с помощью источников на основе ВИЭ совместно с дизель-генератором $G S$ без накопителя электроэнергии

Возможные варианты модификации схемы $\mathrm{T}_{3} 1$ указаны в таблице 3 .

Таблица 3

Список возможных вариантов схемы типа $\mathbf{T}_{3} \mathbf{l}$

\begin{tabular}{|c|l|c|}
\hline Тип системы & \multicolumn{1}{|c|}{ Источник электроэнергии } & $\begin{array}{c}\text { Род тока } \\
\text { напряжения на } \\
\text { выходе системы }\end{array}$ \\
\hline T3I-a & $\begin{array}{l}\text { Постоянный ток, например: фотоэлектрический } \\
\text { модуль (PV-модуль) }\end{array}$ & Постоянный ток \\
\hline $\mathrm{T}_{3} \mathrm{I}-\mathrm{b}$ & Переменный ток, например: ветродвигатель & Переменный ток \\
\hline
\end{tabular}


В системах типа $\mathbf{T}_{\mathbf{3}} \mathbf{l}$-a накопитель отсутствует, но требуется устройство минимальной емкости для накопления электроэнергии, необходимое для поддержания соответствующего уровня напряжения.

Система типа T4l - Производство с помощью источников

на основе ВИЗ совместно с дизель-генератором $G S$ при наличии

\section{накопителя электроэнергии}

Система типа T4l (рис. 7) может поддерживать энергоснабжение в случае длительного отсутствия работы ВИЭ. Наличие резервного генератора обеспечивает потребителя электроэнергией даже в случае плохих погодных условий. Система этого типа обеспечивает производство электроэнергии как переменного, так и постоянного тока. В связи с этим необходимы две отдельные цепи распределения электроэнергии [2].

Электроснабжение напряжением переменного тока обычно осуществляют от аккумуляторной батареи через инвертор. Включение генераторной установки необходимо при:

- периодической подзарядке аккумуляторов (профилактика, компенсация саморазряда);

- обязательной подзарядке аккумуляторов при индикации низкого напряжения на выходе аккумуляторной батареи устройством управления потреблением электроэнергии;

- необходимости подведения электроэнергии к оборудованию потребителя в случае невозможности использования возобновляемых источников энергии.

Наличие генераторной установки позволяет обеспечить поставку электроэнергии в те периоды времени, когда невозможно или нежелательно ее осуществлять с использованием возобновляемых источников энергии [2]. 


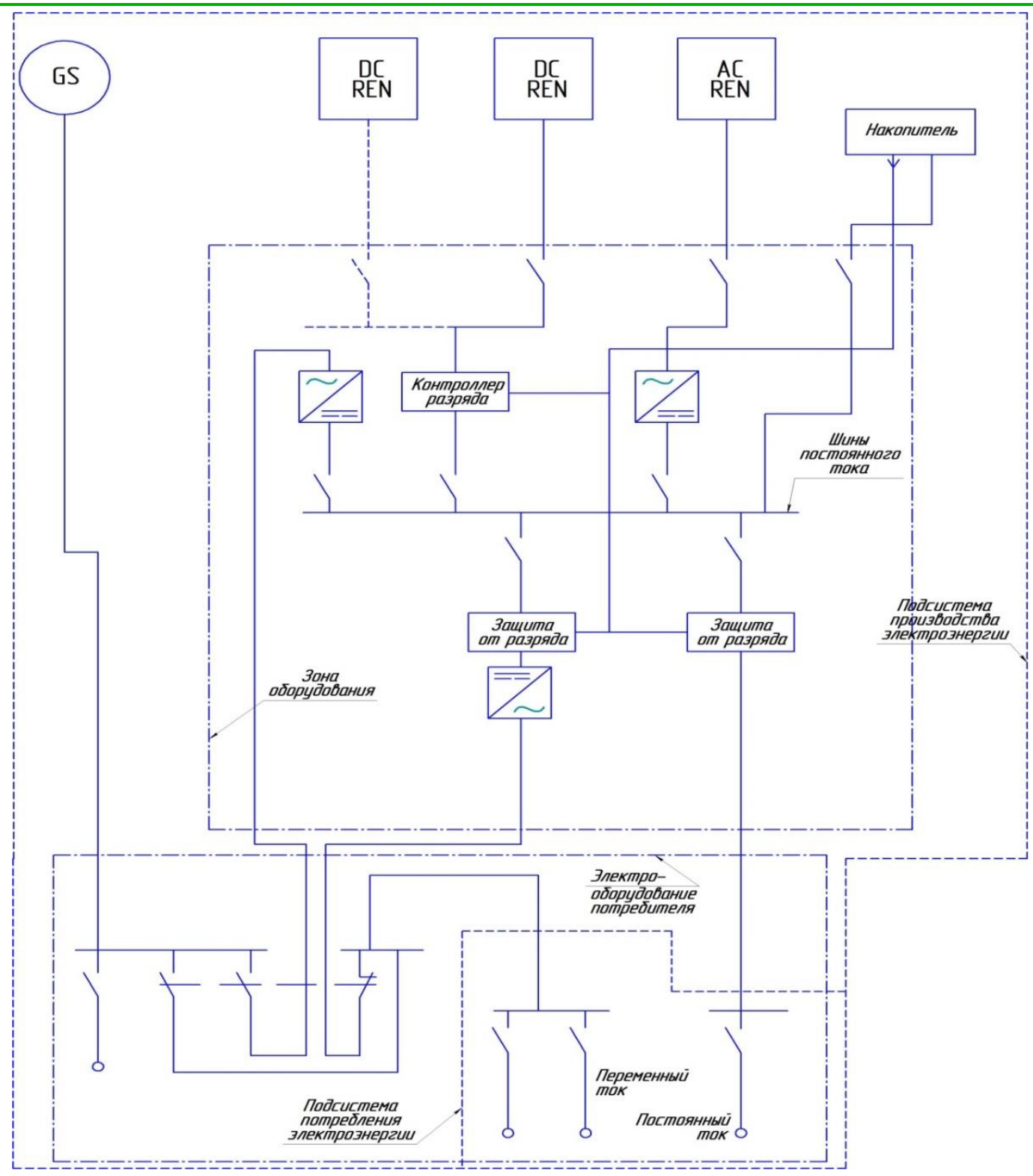

Рис. 7. Система типа $T_{4} 1$ - Производство с помощью источников на основе ВИЗ совместно с дизель-генератором $G S$ при наличии накопителя

\section{электроэнергии}

Снабжение электроэнергией потребителей может производиться:

- напряжением постоянного тока;

- напряжением переменного тока. В этом случае при отказе в системе электроснабжение напряжением переменного тока обеспечивается генераторной установкой. Генераторная установка и ВИЭ одновременно снабжать электроэнергией потребителя не могут;

- напряжением переменного и постоянного тока (двойное электроснабжение $\mathrm{AC} / \mathrm{DC})$; 
- напряжением переменного и постоянного тока с одновременным использованием напряжения переменного тока для питания генераторной установки.

Заключение. Представленные функциональные схемы могут быть использованы при разработке децентрализованных индивидуальных систем электроснабжения с возобновляемыми источниками энергии для одиночных потребителей. При конкретном проектировании определяют количественные показатели энергопотребления, показатели качества электрической энергии, размеры различных частей системы: генераторов, накопителей, выключателей, устройств защиты.

\section{Список литературы}

1. ГОСТ Р 56124.1-2014 Возобновляемая энергетика. Гибридные электростанции на основе возобновляемых источников энергии, предназначенные для сельской электрификации. Рекомендации. Часть 1. Общее введение для сельской электрификации. - М.: Стандартинформ, 2016. - 13 с.

2. Возобновляемая энергетика. Гибридные электростанции на основе возобновляемых источников энергии, предназначенные для сельской электрификации. Рекомендации. Ч. 2. Из требований по классификации систем электроснабжения. - М.: Стандартинформ, 2016. $52 \mathrm{c}$.

3. Андрианова Л.П. Системы децентрализованного электроснабжения сельских объектов на базе фотоэлектрических модулей / Л.П. Андрианова, А.Е. Усманова, В.А. Александров // Наука молодых - инновационному развитию АПК : Материалы 11 Национальной научно-практической конференции молодых ученых. 4 декабря 2018. Часть 2 . - Уфа: Башкирский ГАУ, 2018. 368 c. - C. $3-8$.

4. Андрианова Л.П. Конфигурации солнечных фотоэлектрических генераторов децентрализованных систем электроснабжения / Л.П. Андрианова, А.Е. Усманова, В.А. Александров // Международная научно-практическая конференция «Проблемы и перспективы разработки инновационных технологий», 15 мая 2019 г. - Стерлитамак. Научно-издательский центр АЭТЕРНА. - Стерлитамак, 2019. - 62 с. - С. 3-6

(ㄱ Л.П. Андрианова, А.И. Гузаиров, Д.М. Голубев, 2021 